

\title{
Distribuição Espacial do Índice Regional de Crédito Rural para as Microrregiões do Rio Grande do Sul (2000-2015)
}

\author{
Spatial Distribution of Regional Rural Credit \\ Index for the Micro-Regions of Rio Grande do Sul \\ (2000-2005)
}

\author{
Leticia Favaretto* | Juliana Favaretto** | Reisoli Bender Filho*** \\ Daniel Arruda Coronel ${ }^{* * * *}$ | Rita Ines Paetzhold Pauli ${ }^{* * * * *}$
}

\begin{abstract}
Resumo
O crédito rural tem um importante papel como instrumento de política agrícola e promotor do desenvolvimento da agropecuária, uma vez que permite uma maior integração técnica da indústria com a agricultura, apesar da tendência à concentração regional. Neste sentido, este estudo teve por objetivo analisar a distribuição espacial do crédito rural em relação ao valor adicionado pela produção agropecuária para as microrregiões do Estado do Rio Grande do Sul, a partir da aplicação do Índice Regional de Crédito Rural, para os anos de 2005, 2010 e 2015. Entre os resultados, destacam-se: (i) desigualdades na distribuição do crédito rural, processo que se concentrou nas microrregiões que apresentaram os maiores IRCR, entre elas Campanha Ocidental, onde prevalecem propriedades ligadas à atividade pecuária; Caxias do Sul e Não-Me-Toque, regiões com diversas empresas ligadas ao ramo do setor do agroindustrial, Porto Alegre, microrregião com maior número de instituições financeiras e; (ii) que a média do IRCR superior à unidade, de 1,48, demonstra que o estado obteve participação maior na distribuição do crédito rural em relação ao $V A B$ da Agropecuária.
\end{abstract}

Palavras-chave: Crédito Rural. Valor Adicionado Agropecuário. Rio Grande do Sul.

\begin{abstract}
The rural credit plays an important role as instrument of agricultural policy and, promoter of agriculture and livestock development, once that it allows a greater technical integration of industry as agriculture, in spite of the tendency to regional concentration. This study aimed to analyze the spatial distribution of rural credit in relation to the value added by the agriculture and livestock production for the micro-regions of Rio Grande do Sul state, from the application of the Regional Rural CreditIndex (IRCR), for the years 2005, 2010 and 2015. Among the results, we highlight: (i) inequalities in distribution of rural credit, process which concentrated itself in the micro-regions that presented the greatest IRCR, among them Campanha Ocidental where prevailed properties linked to livestock activity; Caxias do Sul and Não-Me-Toque, regions with several companies linked to the branch of agriculture and livestock sector and; Porto Alegre, micro-region with the greatest number of financial institutions and; (ii) that the average of IRCR superior to unit, of 1.48 , demonstrates that the state obtained greater participation in distribution of rural credit in relation to VAB of Agriculture and Livestock.
\end{abstract}

Keywords: Rural Credit; Agriculture and Livestock Added Value; Rio Grande do Sul.

\footnotetext{
* Bolsista de Iniciação Científica (PIBIC) do CNPq. https://orcid.org/0000-0003-4868-0335. E-mail: leticiafavaretto18@gmail.com

** Bolsista de Iniciação Científica (PIBIC) do CNPq. https://orcid.org/0000-0002-3140-146X. E-mail: julianafavaretto07@hotmail.com

*** Professor Associado do Curso de Graduação em Ciências Econômicas da UFSM e Bolsista de Produtividade do CNPq, UFSM. https://orcid.org/0000-0002-1019-4414. E-mail: reisolibender@yahoo.com.br

**** Professor Associado do Curso de Graduação em Ciências Econômicas e dos Programas de Pós-Graduação de Economia e Desenvolvimento, Gestão de Organizações Públicas e Agronegócios da UFSM e Bolsista de Produtividade do CNPq, UFSM. https://orcid.org/0000-0003-0264-6502. E-mail: daniel.coronel@uol.com.br

***** Professora Associada do Curso de Graduação em Ciências Econômicas da UFSM.

https://orcid.org/0000-0001-9910-5301.E-mail: rita.pauli@gmail.com
}

http://dx.doi.org/10.51861/ded.dmv.2.003 - Recebido em 12 de maio de 2020. Aceito em 15 de julho de 2020. 


\section{INTRODUÇÃO}

A agricultura e a pecuária desempenham um papel relevante na história econômica brasileira, tanto na produção de alimentos e matérias-primas como no fornecimento de mão de obra para outros setores, além da geração de excedentes exportáveis que garantem o superávit da balança comercial e de ser essencial não só na oferta interna de alimentos para suprir a demanda final como também insumo para a indústria. Em termos históricos, o principal instrumento de fomento da agricultura e da pecuária foi a política de crédito rural viabilizada pelo Sistema Nacional de Crédito Rural (SNCR), o qual se destaca como um dos mais importantes mecanismos de financiamento agropecuário, constituindo-se como um impulsionador para o desenvolvimento do setor (ALMEIDA et al., 2008).

O crédito rural continua sendo essencial para o desenvolvimento agropecuário, porém, ao longo das décadas, sua estrutura de oferta foi sendo moldada aos diferentes contextos econômicos. Na década de 1970, quando foi instituído, concentrou-se em alguns produtos, especialmente aqueles voltados para a exportação ou à comercialização, e também em favor de algumas regiões, caso da Sul e da Sudeste (HOFFMANN \& KAGEYAMA, 1987). Além de beneficiar algumas regiôes e as culturas de exportação, o crédito rural beneficiou também médios e grandes proprietários (BACHA, 2004). Esse contexto mostra que, historicamente, a política de crédito rural contribuiu na promoção de uma maior concentração regional.

Ainda, nas décadas de 1980 e 1990, a oferta de crédito reduziu-se drasticamente, em função das mudanças de estratégia econômica e dos problemas com o crédito rural, decorrentes da desarticulação entre juros e preços agrícolas (GALEANO, SILVA \& SOUZA, 2017). Portanto, durante estas décadas, não devido a uma intenção governamental, mas à falta de recursos de fomento, a política de crédito rural perde relevância e é parcialmente substituída pela Política de Preços Mínimos (PPM).

Em 1996, com a articulação de organizações sociais que pressionaram o governo para que houvesse uma política diferenciada de crédito rural para a agricultura familiar, surgiu o Programa Nacional de Fortalecimento da Agricultura Familiar (PRONAF). O programa é uma das mais importantes políticas voltadas para o meio rural, visto que está presente na maioria dos municípios e possibilita mais democratização e acesso ao crédito para o maior setor da agricultura, que era também o mais fragilizado, pois tinha capacidade técnica limitada, dificuldade de inserção nos mercados agropecuários e, além disso, diversas restriçốes de recursos (MATTEI, 2014). Vale destacar que se trata de um programa de grande relevância, especialmente para os estados com grande número de pessoas ocupadas na 
agricultura familiar, caso do Rio Grande do Sul, que está entre os três maiores estados em número de pessoas ocupadas nesta atividade (FEIX \& LEUSIN JUNIOR, 2019).

Especificamente, o crédito rural consiste na destinação de recursos para a contratação de operaçóes de crédito aos produtores rurais e agricultores familiares para o custeio da safra, investimentos em suas propriedades, apoio à comercialização de seus produtos ou à industrialização. Esta modalidade de crédito é operacionalizada pelos bancos integrantes do Sistema Nacional de Crédito Rural, autorizados pelo Banco Central do Brasil (MINISTÉRIO DA ECONOMIA, 2018).

Dentro desta modalidade creditícia, os créditos de custeio são recursos que se destinam a cobrir despesas habituais dos ciclos produtivos, da compra de insumos à fase de colheita. Os créditos de investimento são aplicados em bens ou serviços duráveis, sendo que seus benefícios repercutem durante muitos anos. Por fim, os créditos de comercialização asseguram ao produtor rural e as suas cooperativas recursos necessários à adoção de mecanismos que garantam o abastecimento e levem ao armazenamento da colheita nos períodos de queda de preço. O produtor pode pleitear as três modalidades de crédito rural como pessoa física ou jurídica, e as cooperativas rurais também são beneficiárias do sistema (MINISTÉRIO DA AGRICULTURA DA PECUÁRIA E DO ABASTECIMENTO, MAPA, 2019).

Decorrente desta discussão, o estudo tem como objetivo principal analisar a distribuição do crédito rural em relação ao valor adicionado pela produção agropecuária às microrregióes do estado do Rio Grande do Sul, a partir da utilização do cálculo do Índice Regional de Crédito Rural (IRCR), para os anos de 2005, 2010 e 2015. Complementarmente, busca-se (i) examinar a evolução da distribuição do crédito rural no período analisado e (ii) identificar deslocamentos e concentraçóes destes recursos.

A importância do crédito rural como instrumento de política agrícola na promoção do desenvolvimento agropecuário, apesar da tendência à concentração regional dos recursos, justifica a análise de sua distribuição espacial ao longo dos últimos anos. Nesta perspectiva de análise, para o Rio Grande do Sul (RS), encontram-se alguns estudos, caso de Schneider et al. (2005), Fagundes e Viana (2017), bem como para municípios específicos, como o de Moraes, Medeiros e Matte Jr (2018) e Oliveira, Oliveira e Pauli (2018). Entretanto, o trabalho avança ao calcular o índice de crédito e avaliar a sua distribuição entre as microrregióes do estado.

Destaca-se também a relevância da discussão para o desenvolvimento local e regional rural gaúcho. O mapeamento da participação das microrregióes do Rio Grande Sul no crédito rural, comparada com sua participação no 
valor adicional bruto agropecuário, permite identificar distorções em sua distribuição e, a partir disso, sugerir medidas para o fortalecimento desta política pública e potencializar seus efeitos locais, gerando melhores resultados para todos os agentes envolvidos no meio rural, bem como nos demais elos das cadeias do setor agropecuário de cada microrregião.

Em termos estruturais, o trabalho está dividido em cinco seçôes. Esta seção preambular traz a abordagem introdutória sobre o crédito rural; a segunda apresenta a revisão literária de estudos empíricos; na terceira, são apresentados os aspectos metodológicos da pesquisa, na quarta, são explicitados os resultados encontrados para a distribuição do crédito rural nas microrregiões do Rio Grande do Sul, e na quinta e última, são apresentadas as conclusões do trabalho.

\section{REVISÃO DE ESTUDOS EMPÍRICOS}

O crédito rural é um instrumento que contribui ativamente para o desenvolvimento rural, sendo que sua distribuição é um tema largamente pesquisado. Por meio destes estudos, pode-se analisar a concentração em determinadas regióes e em determinadas culturas, seja ela para o país, para estados, por regiões ou mesmo municípios.

Souza, Ney e Ponciano (2011) analisaram a distribuição dos financiamentos do PRONAF entre as unidades da federação, no período 1999-2009. Para verificar a distribuição da agricultura familiar e recursos do PRONAF, foram utilizados indicadores de concentração e desigualdade, como a Razão de Concentração, o Índice T de Theil e o Índice de Gini. Os resultados mostraram uma tendência de desconcentração dos recursos até 2006, especialmente na linha de investimento, entretanto, nos anos seguintes, a distribuição do crédito voltou a se concentrar. Indicaram também que os Estados do Rio Grande do Sul, Paraná, Minas Gerais e Santa Catarina são os maiores receptores de crédito do programa. Ainda, o estudo constatou que a distribuição do crédito não reflete totalmente a distribuição da agricultura familiar e, especialmente, os recursos de custeio vêm privilegiando estados com maior participação no valor da produção familiar.

Jesus e Castro (2012) analisaram a distribuição do crédito agrícola no Estado de São Paulo, durante o período de 1999 a 2009, a partir da utilização $\mathrm{da}$ metodologia do Índice $\mathrm{T}$ de Theil. $\mathrm{O}$ trabalho considerou três níveis de agregação regional, mesorregião, microrregião e municípios a fim de determinar o índice total do estado. Os resultados revelaram que o índice de desigualdade cresceu ao longo do período estudado, além disso, nas microrregióes, o crédito está concentrado apenas em um ou em poucos municípios. 
Os autores constaram que a desigualdade na distribuição do crédito aumenta quando se considera a distribuição em níveis mais desagregados e também que o aumento do volume de crédito foi acompanhado por um aumento na desigualdade.

Fagundes e Viana (2017) desenvolveram estudo sobre a evolução do crédito rural no Rio Grande do Sul para compreender seu histórico e funcionalidades, tendo como objetivo analisar o crédito de forma ampla e também por setores da atividade agrícola e pecuária entre os anos de 2006 e 2016. Metodologicamente, os autores realizaram uma análise quantitativa de estatística descritiva. Os resultados evidenciaram que o setor agrícola apresenta maior disponibilidade de crédito não apenas em termos de volume de recursos, mas também no número de contratos, sendo o crédito de custeio a linha com maior disponibilidade em relação ao total de crédito para a agricultura. Em relação à pecuária, a demanda por linhas de custeio e investimento é proporcional, e a linha de comercialização é inexpressiva tanto para o setor agrícola quanto para o pecuário. Em relação à evolução, observou-se um aumento no volume de crédito entre 2006 e 2014, e, a partir desse último ano, uma queda relativa devido à retração econômica do país.

Galeano, Silva e Souza (2017) estudaram a distribuição do crédito rural para os municípios do Espírito Santo, comparando com os demais estados do Brasil, no período de 1999 a 2013. O trabalho utilizou a metodologia do Índice Regional de Crédito Rural (IRCR). Os resultados encontrados indicaram que, de forma geral, a distribuição do crédito rural entre os municípios e os estados não acompanha sua participação relativa no valor adicionado da agropecuária. O estudo mostrou ainda que, até o ano de 2009, o Espírito Santo teve uma participação menor no crédito do que no valor adicionado da agropecuária. E, ao apresentar um mapeamento do IRCR dos municípios, evidenciou quais poderiam aumentar seus investimentos no meio rural a partir desta política pública.

Ainda, nesta perspectiva, Souza, Santos e Rebello (2018) avaliaram a distribuição espacial e a concentração de crédito rural no Brasil, entre 2007 e 2017. A metodologia empregada foi o uso do Índice Normalizado de Crédito Rural (INCR) para caracterizar a espacialização das atividades financiadas nas unidades da federação e o índice de Gini para verificar a concentração nos segmentos produtivos. Os resultados indicaram expressiva concentração na aplicação de recursos, dado que cerca de $71,42 \%$ de todo o volume aplicado entre 2007 e 2017 concentrou-se em seis unidades da federação, quais sejam: Paraná, Rio Grande do Sul, São Paulo, Minas Gerais, Goiás e Mato Grosso, sobretudo em financiamentos agrícolas. O INCR permitiu identificar padrões diferentes de especialização quanto à aplicação do crédito, sendo 
que, nas regióes Norte e Nordeste, os recursos foram, em sua maioria, à pecuária e, na Região Sudeste, para as atividades agrícolas.

\section{METODOLOGIA}

A mensuração da importância do crédito rural e sua distribuição em um contexto ampliado foi efetuada a partir de uma breve revisão da literatura empírica, enquanto que os procedimentos metodológicos compreendem a construção do Índice Regional de Crédito Rural (IRCR), pela utilização de fontes de dados secundários.

\section{Índice Regional de Crédito Rural (IRCR)}

A metodologia do Índice Regional de Crédito (IRC) possibilita mensurar a desigualdade na distribuição de crédito em determinada região. Para isso, o IRC compara a participação de uma região no total de crédito concedido no país com sua participação no PIB nacional (GALEANO et al., 2017). O referido índice foi desenvolvido por Crocco et al. (2011), os quais metodologicamente realizaram uma adaptação do "Quociente Locacional", índice largamente utilizado em economia regional para verificar a existência ou não de especialização produtiva em uma região específica.

A partir da formulação do Índice Regional de Crédito (IRC), estruturou-se o Índice Regional de Crédito Rural (IRCR) com o intuito de analisar especificamente o crédito rural para o estado do Rio Grande do Sul. O IRCR compara a participação de uma microrregião em relação ao total de crédito rural destinado ao estado com a sua participação no Valor Adicionado Bruto da Agropecuária. Formalmente, a construção do Índice Regional de Crédito Rural (IRCR) é apresentado em (1).

$$
I R C R=\frac{\frac{C R E D i}{C R E D r s}}{\frac{V A B i}{V A B r s}}
$$

em que IRCRi é o Índice Regional de Crédito Rural da microrregião $i$; $C R E D i$ o crédito rural para a microrregião $i$; CREDrs o crédito rural para o Rio Grande do Sul; $V A B i$ o valor adicionado bruto da agropecuária da microrregião $i$; e VABrs o valor adicionado bruto da agropecuária do Rio Grande do Sul.

Para fins de análise dos resultados, quando o IRCR for igual à unidade $(I R C R=1)$, a proporção de crédito rural aplicado naquela localidade é igual 
ao VAB agropecuário por ela gerado. No caso do $I R C R$ ser maior que a unidade $(I R C R>1)$, a região está tendo uma participação maior na distribuição do crédito rural do que sua participação na distribuição do VAB agropecuário e, no caso do IRCR ser menor que a unidade $(I R C R<1)$, a região está obtendo participação menor na distribuição de crédito rural do que sua participação no VAB agropecuário. Para o Rio Grande do Sul, o cálculo foi feito anualmente, de 2005 a 2015, e, para as microrregióes, foi realizado a cada cinco anos, assim como realizada a distribuição espacial.

Geograficamente, o Estado do Rio Grande do Sul está dividido em 497 municípios, distribuídos em 35 microrregióes, conforme o Instituto Brasileiro de Geografia e Estatística - IBGE (2020). A partir desta estrutura, optou-se por calcular o índice por microrregióes em decorrência da grande quantidade de municípios, o que dificultaria a avaliação. Ademais, a análise por microrregiões permite que, em ocorrendo diferenças microrregionais consideráveis, possa se aprofundar o estudo em nível municipal, para identificar os municípios que se distanciam das características dos circunvizinhos.

\section{Fonte dos Dados}

Os dados utilizados correspondem ao valor total do crédito rural, que engloba os créditos para custeio, investimento e comercialização para as microrregióes do Rio Grande do Sul e para o Brasil, coletados no site do Banco Central do Brasil (BACEN); o valor adicionado bruto da agropecuária (VAB) das microrregióes do Rio Grande do Sul foi coletado no sítio da Fundação de Economia e Estatística (FEE) e o valor adicionado bruto da agropecuária (VAB) para o país foi coletado no sítio do IPEADATA, mas, ambos são divulgados pelo IBGE/SCN. Este conjunto de dados possui frequência anual, compreendendo os anos de 2005 até 2015, os quais foram utilizados para calcular o índice para as 35 microrregióes do Rio Grande do Sul.

\section{ANÁLISE E DISCUSSÃO DE RESULTADOS}

Esta seção tem o objetivo de apresentar a distribuição do crédito rural em relação ao valor adicionado da produção agropecuária do Estado do Rio Grande do Sul e de suas às microrregióes, a partir dos resultados do Índice Regional de Crédito Rural, para os anos de 2005, 2010 e 2015, a fim de examinar a evolução da distribuição do crédito rural e identificar se houve deslocamentos elou concentraçóes destes recursos. 


\section{Divisões Regionais e Aspectos Econômicos}

Ao analisar as especificidades econômicas e geográficas, o Estado do Rio Grande do Sul pode ser dividido em sete mesorregiôes, que compreendem 35 microrregiốes (Tabela 1). Destaca-se que a produção agropecuária está entre as primeiras e mais tradicionais atividades econômicas do estado.

Tabela 1 - Mesorregiões e Microrregiões do Rio Grande do Sul

\begin{tabular}{l|l}
\hline MESORREGIÃO & MICRORREGIÕES \\
\hline Noroeste Rio-Grandense & $\begin{array}{l}\text { Santa Rosa, Três Passos, Frederico Westphalen, Erechim, Sananduva, } \\
\text { Cerro Largo, Santo Ângelo, ljuí, Carazinho, Passo Fundo, Cruz Alta, } \\
\text { Não-Me-Toque e Soledade. }\end{array}$ \\
\hline Nordeste Rio-Grandense & Guaporé, Vacaria e Caxias do Sul. \\
\hline Centro Oriental Rio-Grandense & Santa Cruz do Sul, Lajeado-Estrela e Cachoeira do Sul \\
\hline Metropolitana de Porto Alegre & $\begin{array}{l}\text { Montenegro, Gramado-Canela, São Jerônimo, Porto Alegre, Osório } \\
\text { e Camaquã }\end{array}$ \\
\hline Sudoeste Rio-Grandense & Campanha Ocidental, Campanha Central e Campanha Meridional \\
\hline Sudeste Rio-Grandense & Serras de Sudeste, Pelotas, Jaguarão e Litoral Lagunar. \\
\hline Centro Ocidental Rio-Grandense & Santa Maria, Santiago e Restinga Seca \\
\hline
\end{tabular}

Fonte: Elaboração própria dos autores

As mesorregiốes Sudeste, Sudoeste e Centro Ocidental possuem a economia baseada principalmente na pecuária extensiva e segmentos complementares como charqueadas e frigoríficos, e a produção e o beneficiamento de arroz também são atividades importantes, ao passo que, nos anos recentes, a cultura da soja tem ampliado sua participação. Os estabelecimentos rurais, nesta parte do estado, devido a condicionantes históricos e econômicos, são, em sua maioria, de médio e de grande porte (PAINEL DO AGRONEGÓCIO, 2019), estrutura que fez com que, em 2015, esta região fosse a que mais contribuiu para o VAB agropecuário do estado, conforme Atlas Socioeconômico do Rio Grande do Sul (2019).

A mesorregião Noroeste caracteriza-se especialmente pelas pequenas e médias propriedades. Historicamente, esse território era caracterizado pela existência de uma produção agrícola diversificada, mas, recentemente, essas áreas produtivas deram lugar às lavouras mecanizadas de soja e trigo. Ademais, essa mesorregião caracteriza-se por apresentar uma rede urbana densa (SOBARZO, 2015). Tal configuração permitiu o desenvolvimento recente, em alguns municípios dessa mesorregião, de indústrias vinculadas à agricultura, como indústrias de alimentos, e concentram um número considerável de grandes e médias empresas de atividade agroindustrial. 
Já a mesorregião Nordeste conta com um polo metalmecânico, agroindustrial, moveleiro e de madeira. Essa mesorregião abrange as microrregióes Guaporé, Vacaria e Caxias do Sul, as quais destacam-se no cultivo de videira para a produção de vinho e espumantes, especialmente na Serra Gaúcha, e hortifrutigranjeiros, com destaque para a maçã na microrregião de Vacaria.

$\mathrm{Na}$ mesorregião Metropolitana, as atividades vinculam-se, principalmente, aos serviços e à indústria, em especial, às indústrias petroquímica, de couro e calçados, química e farmacêutica, papel e celulose. O turismo também se destaca, especialmente em Gramado e Canela. É a mesorregião que possui a maior concentração urbana do estado, justamente pela grande oferta de empregos na indústria e serviços.

Na mesorregião Centro Oriental, destaca-se a produção de fumo, cultura desenvolvida em pequenas propriedades familiares e tem grande parte da produção distribuída às indústrias de transformação e beneficiamento localizadas especialmente na microrregião Santa Cruz do Sul. A criação de aves e suínos também é uma atividade importante sobretudo para os municípios da microrregião Lajeado-Estrela. Além destas atividades, a silvicultura também se destaca nesta mesorregião (ATLAS SOCIOECONÔMICO DO RIO GRANDE DO SUL, 2019).

Conforme observado, a estrutura produtiva nas mesorregióes é heterogênea, embora com predominância da atividade agropecuária. A análise das atividades econômicas em cada região do estado bem como as suas características específicas auxiliam na compreensão dos resultados quanto à distribuição do crédito e ao valor que elas adicionam na agropecuária.

Índice Regional de Crédito Rural (IRCR) para o Estado do Rio Grande do $\mathrm{Sul}$

O crédito rural é um financiamento destinado, na sua maior parte, para produtores rurais com o objetivo de estimular os investimentos, contribuir no custeio da produção e comercialização de produtos agropecuários, além de fortalecer o setor rural, estimulando geração de renda, melhorando o uso da mão de obra na agricultura familiar (MAPA, 2019), minimizando o êxodo rural e estimulando o uso de novas tecnologias no campo. Conforme discutido, os recursos do crédito rural são prioritariamente destinados ao crédito de custeio, o que, apesar de importante, é insuficiente quando se tem a necessidade de alavancar recursos para investimento, essenciais para acompanhar os processos de modernização tecnológica da agricultura frente à competitividade internacional.

Nota-se que o volume de recursos financeiros que o Brasil disponibilizou de crédito rural, entre 2005 a 2014, aumentou continuamente a cada ano, 
reduzindo-se em 2015, resultado que pode ser justificado pela crise de liquidez decorrente da recessão econômica. Neste período, a taxa média de crescimento anual do crédito rural brasileiro atingiu $15,8 \%$, conforme se visualiza na Figura 1.

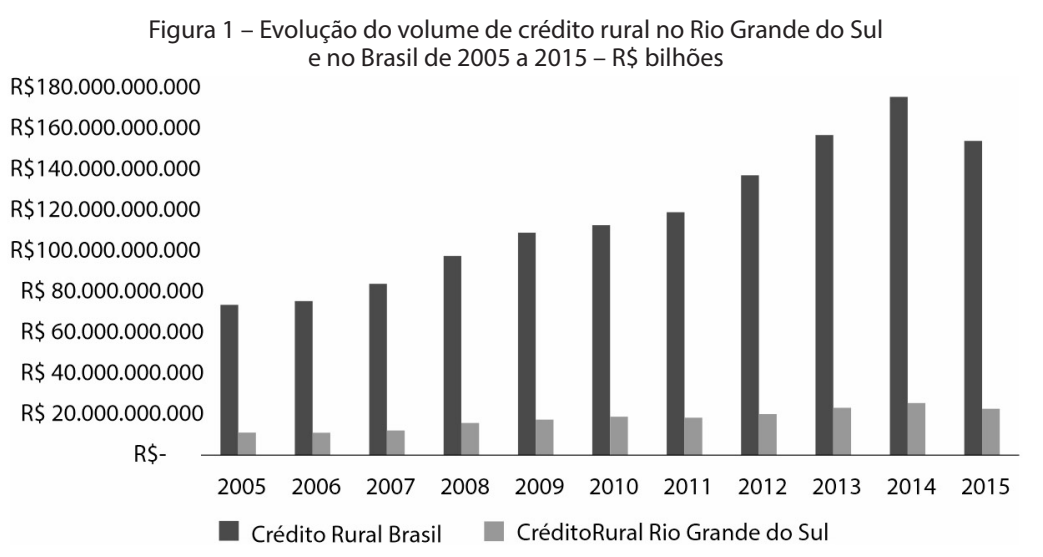

Fonte: Elaborado pelos autores, com base em dados do BACEN e da FEE (2019), deflacionados pelo IGP-DI (2015)

Destaca-se que a concessão do crédito rural para o Rio Grande do Sul acompanhou proporcionalmente esse aumento, apresentando taxa média de crescimento anual de $15,7 \%$. Convém destacar que esse aumento em volume do crédito rural não está associado apenas aos objetivos de aumentar a produção agrícola e pecuária, mas considera a elevação dos custos de produção ao longo dos anos.

Em relação ao Valor Adicionado Bruto da agropecuária brasileira, conforme Figura 2, a participação média do estado gaúcho, para o período, foi menor, de 10,45\% (FEE, 2019). Apesar disso, o Rio Grande do Sul está entre os estados que mais contribuem para o VAB da agropecuária brasileira e, no ano de 2015, o estado foi o que mais contribui para o total nacional (ATLAS SOCIOECONÔMICO, 2019).

$\mathrm{Na}$ composição do VAB agropecuário do Rio Grande do Sul, a agricultura representa $69 \%$, seguida pela pecuária $(25 \%)$ e, por fim, pela produção florestal, pesca e aquicultura (6\%). Destaca-se também que o setor agropecuário está interligado com a indústria a montante, que fornece insumos, máquinas implementos, assistência técnica entre outros, e com a indústria a jusante no processamento e distribuição da produção, além do mais, a renda excedente gerada pela agropecuária impacta no setor de serviços. Portanto, a atividade agropecuária é uma fonte de dinamismo para a economia do estado (FEIX \& LEUSIN JÚNIOR, 2019). 
Figura 2 - Evolução do Valor Adicionado Bruto da Agropecuária do Rio Grande do Sul e do Brasil de 2000 a 2015 - R\$ bilhões

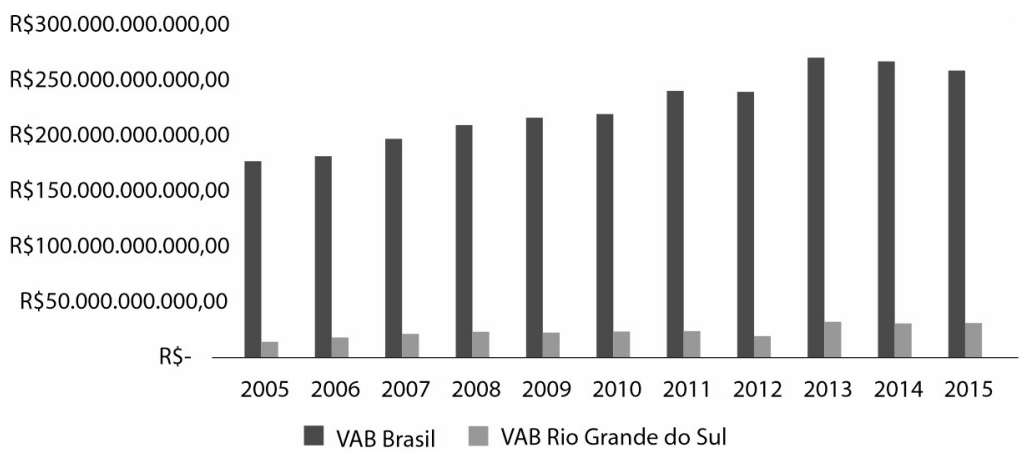

Fonte: Elaborado pelos autores, com base em dados do BACEN e da FEE (2019), deflacionados pelo IGP-DI (2015)

Considerando o crédito e o valor adicionado, a dinâmica da distribuição de crédito rural, analisada a partir do Índice Regional de Crédito Rural (IRCR), para o estado do Rio Grande do Sul, correspondente aos anos de 2005 a 2015, encontra-se na Figura 3. O resultado demonstrou que o estado obteve, durante todo período, um resultado maior que a unidade, indicando que sua participação no volume total de crédito rural manteve-se superior à sua participação no total do valor adicionado bruto da agropecuária. Outra evidência está na variabilidade do IRCR, que variou entre 1,86 e 1,22. Esses resultados, que correspondem aos máximos e mínimos, ocorreram nos extremos do período, com máximo de 1,86 , no ano de 2005 , enquanto o menor IRCR, de 1,22, ocorreu no ano de 2015.

Figura 3 - Evolução do Índice Regional de Crédito Rural do Rio Grande do Sul, no período entre 2005 a 2015

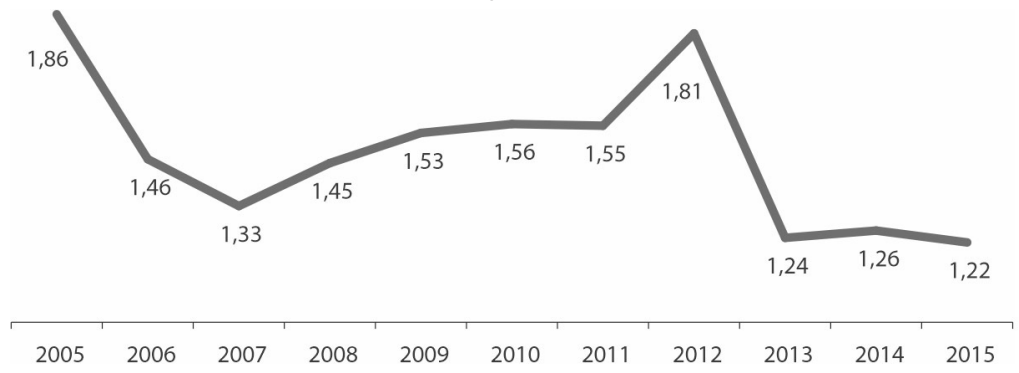

Fonte: Elaborada pelos autores, com base nos dados do BACEN e da FEE (2019) 
Observa-se que, a partir de 2013, esta relação vem caindo sistematicamente, o que está associado ao fato de que a participação do Rio Grande do Sul na distribuição do crédito rural tem diminuído, enquanto a participação no VAB da agropecuária tem crescido ao longo dos anos. Neste período, as condiçôes do mercado interno e externo foram bastante favoráveis, houve aumento da demanda, os preços internacionais se tornaram bastante atrativos, e o volume de crédito rural voltou a aumentar (BELIK, 2015). No entanto, a partir de 2015, pode-se observar queda no volume de crédito rural (BACEN, 2019b).

Conforme Oliveira e Wolf (2016), a partir do início de 2014, a desaceleração da atividade econômica gerou uma redução de demanda por crédito, bem como levou as instituições financeiras a adotarem medidas mais restritivas nas concessões de crédito. A diminuição da concessão de crédito só não foi maior em razão da atuação dos bancos públicos, mas com condições menos favoráveis, com redução do volume, dos prazos e aumento nas taxas de juros.

Já o VAB da Agropecuária no estado apresentou tendência crescente, porém os anos de 2005 e 2012 foram marcados por fortes estiagens, que levaram a uma drástica redução da produção agrícola, condição que torna

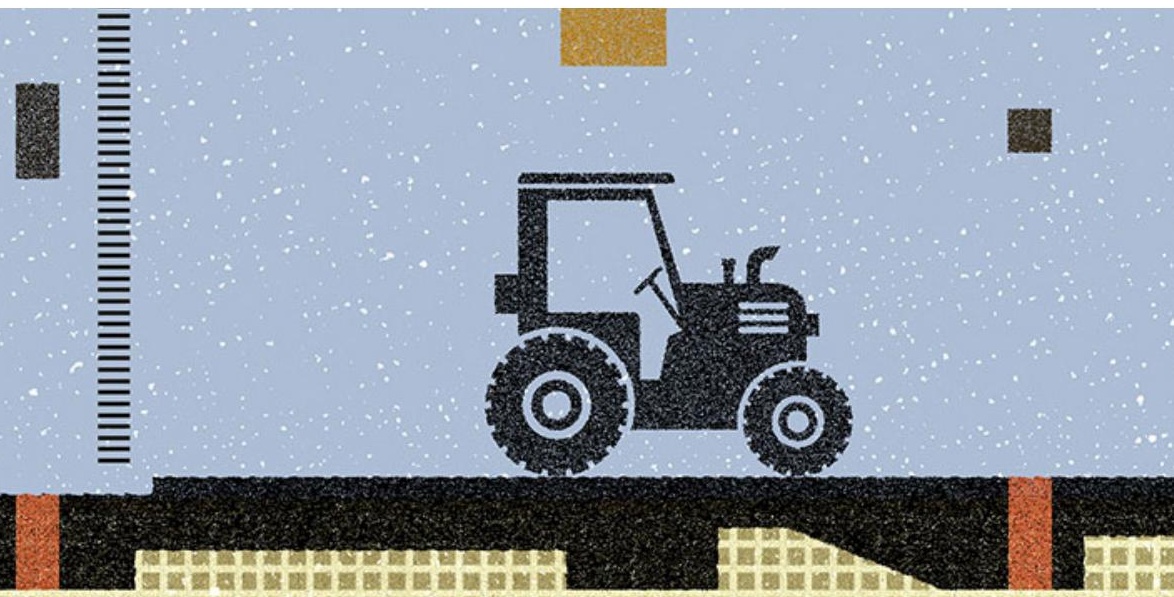

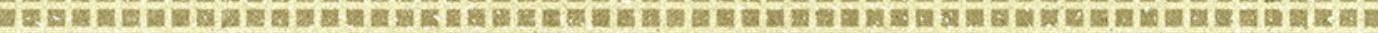

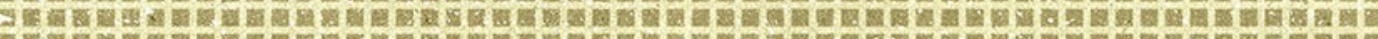

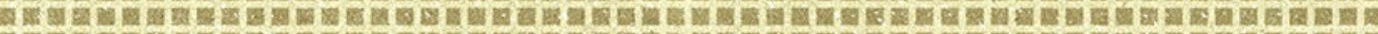

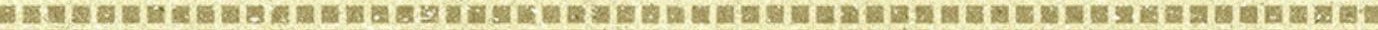

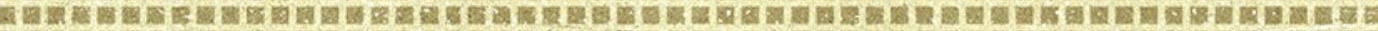

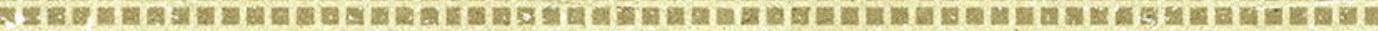
的

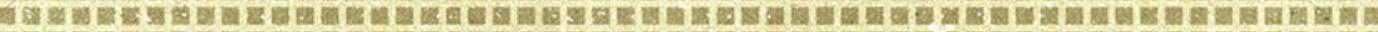

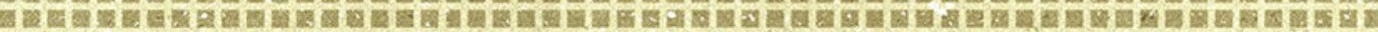

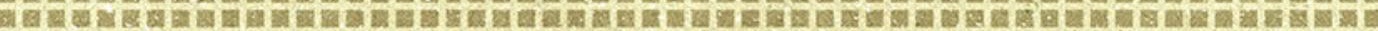

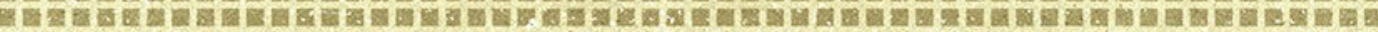

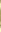

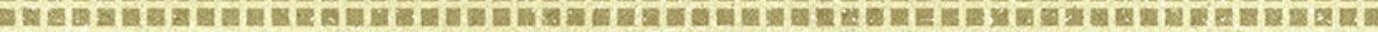

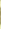

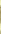

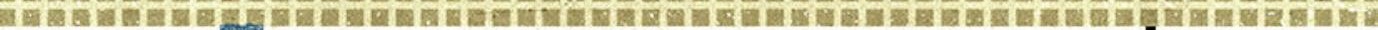


possível explicar o aumento acentuado no IRCR nestes dois anos. Para Feix e Leusin Junior (2019), o aumento do VAB no estado é influenciado pelo rendimento físico por hectare, e este é muito sensível ao clima, além disso as mudanças no uso do solo e inovações físicas e tecnológicas também são condicionantes importantes.

\section{Distribuição Espacial e o Índice Regional de Crédito Rural (IRCR) às Microrregiões do Rio Grande do Sul}

Complementando, analisa-se a distribuição espacial do crédito rural a partir do valor adicionado bruto da agropecuária e do IRCR, às microrregióes do Rio Grande do Sul, nos anos de 2005, 2010, 2015. Os resultados por microrregião e ano encontram-se na Tabela 2.

Nota-se que, para o ano de 2005, as microrregióes que apresentaram os maiores Índices Regionais de Crédito Rural foram Porto Alegre, NãoMe-Toque, Cruz Alta, Sananduva, Carazinho e Ijuí, sendo que as duas primeiras tiveram um índice superior a 2 . A porcentagem de crédito captada por estas regióes foi de aproximadamente $21 \%$ do total do crédito captado pelo estado, enquanto a sua produção agropecuária foi cerca de $11,5 \%$. Com exceção da microrregião Porto Alegre, as demais estão concentradas na mesorregião Noroeste. Neste mesmo ano, as microrregióes com IRCR baixo foram São Jerônimo, Guaporé e Montenegro, as quais, juntas, captaram apenas $4,5 \%$ do total de crédito destinado ao Rio Grande do Sul, enquanto que o valor que adicionaram à agropecuária do estado foi de $8,95 \%$.

No ano de 2010, as microrregiôes com IRCR alto foram Porto Alegre, Campanha Ocidental, Restinga Seca e Caxias do Sul, e estas quatro microrregiôes receberam cerca de $23,7 \%$ do crédito rural destinado ao estado, enquanto participaram com $13 \%$ na formação do valor adicionado da agropecuária. No outro extremo, com os menores IRCR, estão Vacaria, Serras de Sudeste, Frederico Westphalen, Guaporé e São Jerônimo.

Ainda, em 2010, destaca-se a microrregião Porto Alegre, cujo índice foi de 4,34. Nesse ano, a microrregião recebeu $\mathrm{R} \$ 853$ milhóes em recursos de crédito rural, o que é equivalente a aproximadamente $6 \%$ do crédito rural total captado pelo estado, enquanto o valor adicionado bruto da agropecuária foi de aproximadamente $\mathrm{R} \$ 246$ milhóes. Em 2005, a microrregião também apresentou o maior IRCR. Em parte, isto pode ser explicado pelo fato de que os contratos de crédito são feitos nas instituiçóes financeiras, e o produtor pode tomar empréstimos fora de seu município. Como na microrregião existem diversas instituiçôes desta natureza, especialmente na capital, vários contratos são gerados e contabilizados nesses municípios. 
$\frac{n}{0}$

응

เั่

जั

응

$\frac{\sqrt{0}}{\frac{10}{0}}$

음

음

$\stackrel{4}{\circ}$

ㅎํำ

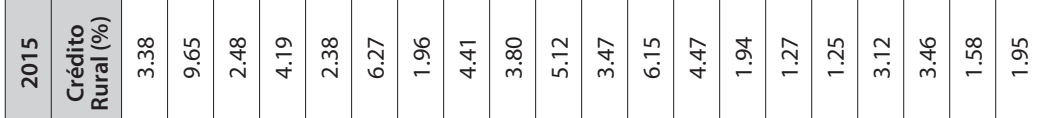

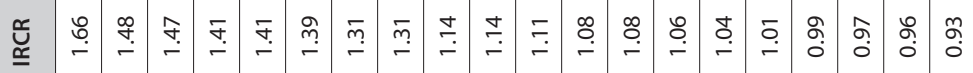

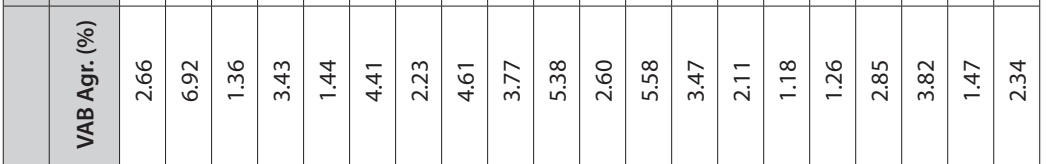

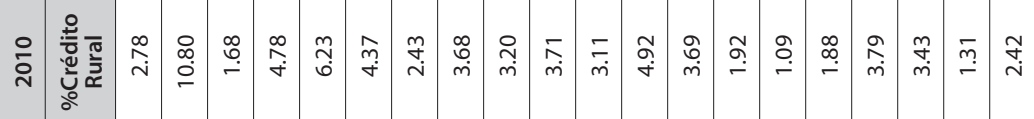

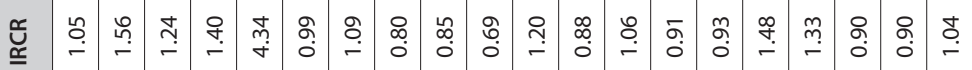

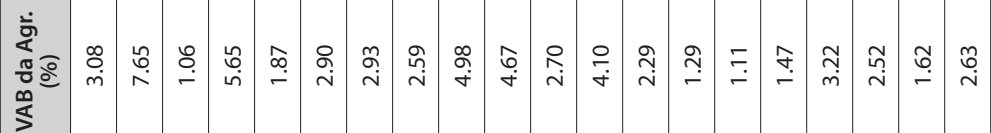

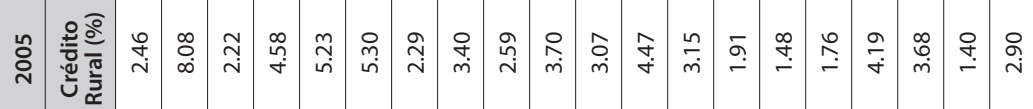

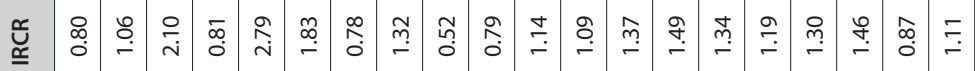

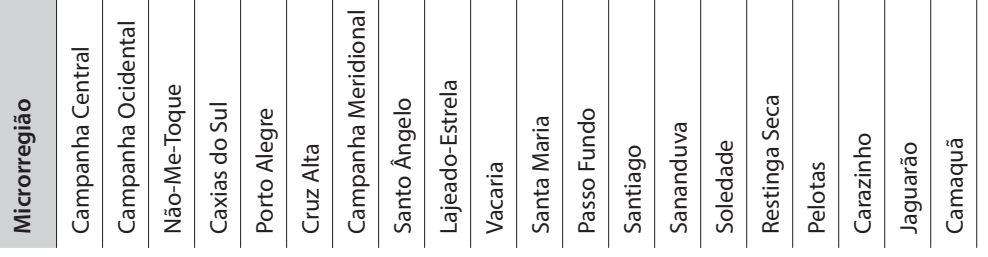




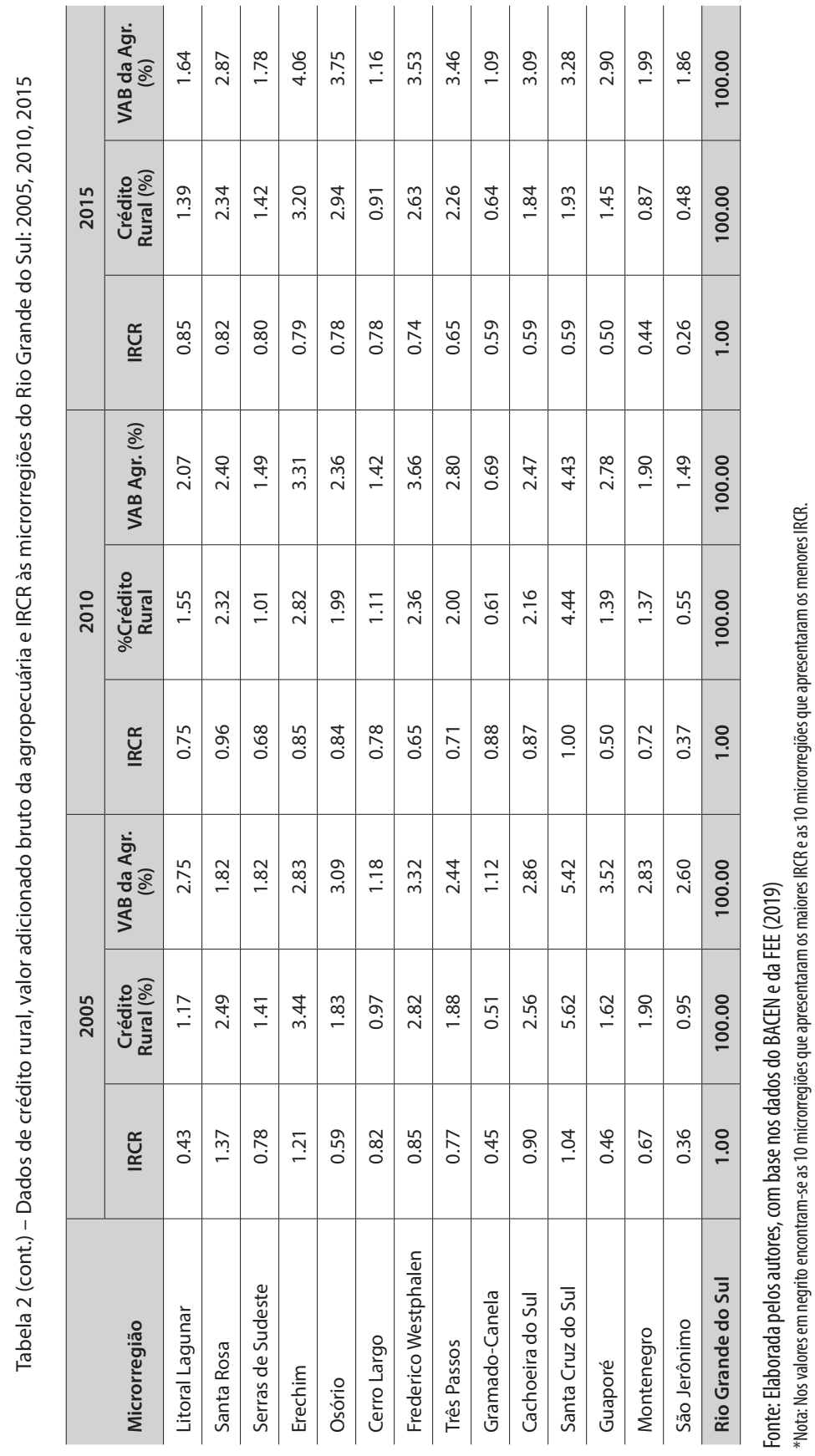


Em 2015, os maiores índices foram nas seguintes microrregióes, em ordem decrescente, Campanha Central, Campanha Ocidental, Não-MeToque, Caxias do Sul e Porto Alegre, a participação conjunta delas no crédito recebido foi de $22,1 \%$ enquanto que a produção agropecuária foi aproximadamente $15 \%$. Além disso, no ano de 2015, nenhuma microrregião obteve o índice maior que 2, sendo o mais elevado de 1,66. Por outro lado, várias regiões tiveram índices baixos, entre elas Três Passos, Santa Cruz do Sul, Cachoeira do Sul, Gramado/Canela, Guaporé, Montenegro e São Jerônimo.

A microrregião Não-Me-Toque apresentou índices superiores à unidade nos três anos analisados. Conquanto tenha conseguido captar elevado volume de crédito rural, a microrregião não conseguiu entregar a produção agropecuária na mesma proporção, resultado que pode residir no município que dá nome à microrregião. Isto é, Não-Me-Toque, que se destaca na fabricação de implementos e máquinas agrícolas, onde atuam diversas empresas ligadas ao ramo agropecuário e de beneficiamento de grãos, atraindo assim muitos investidores. Entretanto, por se tratar de uma microrregião formada por apenas sete municípios, o valor adicionado à agropecuária, em geral, não conseguiu acompanhar o volume de crédito recebido (TATSCH, 2006).

Outra microrregião que se destaca na análise é a Campanha Ocidental, que apresentou IRCR elevado tanto em 2010 quanto em 2015. Esta microrregião é muito relevante para a agropecuária do estado, pois, nos três anos analisados, ela foi a que forneceu maior contribuição ao VAB da agropecuária, entretanto também foi a microrregião que recebeu o maior volume de crédito rural.

Em relação às microrregiốes com IRCR inferior à unidade, encontram-se microrregióes com grande representatividade no VAB da agropecuária estadual, caso de Frederico Westphalen, Guaporé, Montenegro, Cachoeira do Sul, Osório e Três Passos. Nessas microrregiôes, predomina o crédito de custeio, o qual se destina a cobrir despesas dos ciclos produtivos, desde a compra de insumos até a fase de colheita. Estas microrregióes conseguem entregar uma produção agropecuária expressiva com baixos volume de recursos de empréstimos referente ao crédito rural.

Ainda neste contexto, é importante destacar que a atividade agrícola está sujeita à ocorrência de fatores exógenos como intempéries da natureza, doenças e pragas, que elevam os riscos dos produtores. Por isso, inerente à concessão de crédito, existe a possibilidade de inadimplência em seu pagamento (BARROS et al., 2015). De acordo com Melo e Resende Filho (2017), as elevadas taxas de descumprimento dos contratos de crédito rural reduzem a capacidade de financiar do SNCR e a eficiência no uso dos recursos pelos 
produtores, além de gerarem prejuízos ao sistema financeiro nacional e aos cofres públicos.

Outra questão inerente à concessão de crédito rural é o desmatamento. Sobre isso, Assunção, Gandour e Romero Rocha (2013) demonstram que a concessão de crédito rural contribui para o aumento do desmatamento no país. Todavia, "a magnitude do impacto varia de acordo com a principal atividade econômica da região, sendo mais expressiva nos municípios onde a pecuária predomina em relação à produção agrícola” (ASSUNÇÃO; GANDOUR; ROMERO ROCHA, 2013, p. 4). Ainda, o Instituto Brasileiro do Meio Ambiente e dos Recursos Naturais Renováveis - IBAMA ressalta que, no Rio Grande do Sul, o desmatamento de mata nativa ocorre em maior magnitude nas áreas de produção de fumo, em que os agricultores, na maior parte dos casos, lançam mão de recursos do PRONAF.

Para uma melhor interpretação dos resultados quanto à evolução da distribuição do crédito rural bem como se ocorreram deslocamentos elou concentrações do crédito rural entre as regióes analisadas, apresenta-se, na Figura 4, a distribuição espacial do Índice Regional de Crédito Rural para as microrregióes do Rio Grande do Sul, nos anos de 2005, 2010 e 2015.

Figura 4 - Distribuição espacial do Índice Regional de Crédito Rural (IRCR), para os anos de 2005, 2010 e 2015
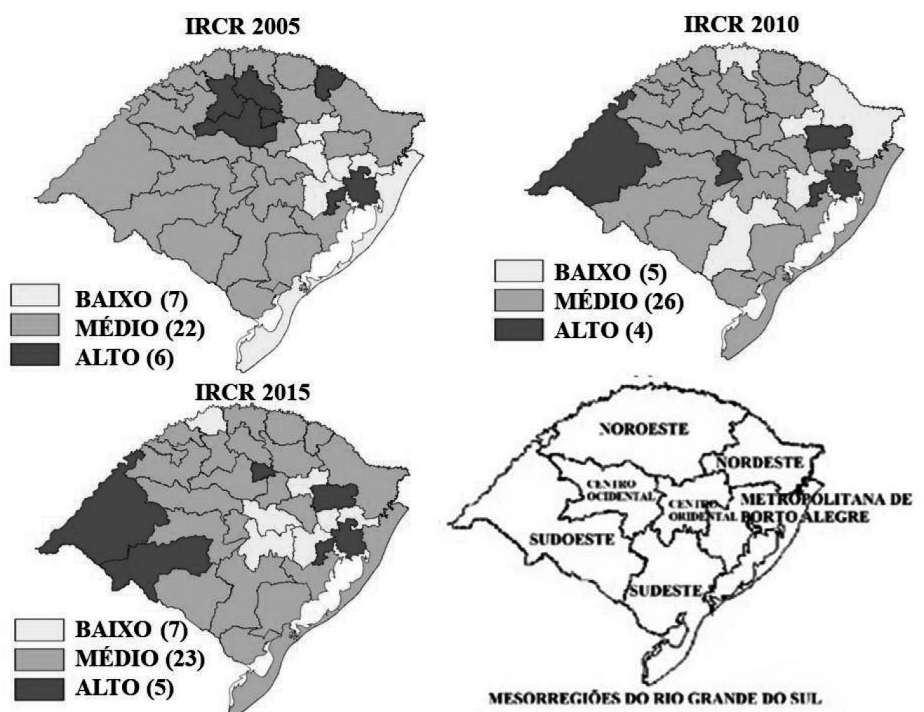

Fonte: Resultados da pesquisa, elaboração própria dos autores

*Nota: IRCR Baixo= menor que 0,7; IRCR Médio = entre 0,7 e 1,40; e IRCR Alto= maior que 1,40. 
A partir dos resultados, observa-se que houve um processo de deslocamento espacial dos maiores IRCR, entre os anos de 2005 e 2010, da microrregião Noroeste para as microrregióes da Campanha (mesorregião Sudoeste), que têm suas propriedades ligadas à atividade pecuária e de baixa rentabilidade da atividade agrícola, e Caxias do Sul, cujas microrregióes possuem diversas empresas ligadas ao ramo do setor do agroindustrial e que, em 2015, concentraram ainda o crédito rural, permanecendo com médio-alto e alto IRCR.

Por fim, os resultados encontrados indicaram que, de forma geral, a distribuição do crédito rural entre as microrregióes não acompanha sua participação relativa no valor adicionado da agropecuária. A partir de 2010, o crédito concentrou-se em microrregiốes específicas do estado, caso da Campanha Ocidental, Caxias do Sul, Não-Me-Toque e Porto Alegre, regióes onde prevalecem propriedades ligadas à atividade pecuária como também outros locais vinculados a setores agroindustriais.

\section{CONCLUSÕES}

O objetivo do artigo foi o de analisar a distribuição espacial do crédito rural nas microrregiôes do Estado do Rio Grande do Sul, para os anos de 2005, 2010 e 2015, a partir da aplicação do Índice Regional de Crédito Rural. Os resultados demonstraram desigualdades na distribuição do crédito rural, processo que se concentrou nas microrregióes que apresentaram os maiores IRCR, entre elas Campanha Ocidental, onde prevalecem propriedades ligadas à atividade pecuária; Caxias do Sul e Não-Me-Toque, regiôes com diversas empresas ligadas ao setor agroindustrial e; Porto Alegre, microrregião com maior número de instituições financeiras.

Por outro lado, constatou-se que as microrregiôes que apresentaram IRCR inferior à unidade, caso de Frederico Westphalen, Guaporé, Montenegro, Cachoeira do Sul, Osório e Três Passos, possuem importante representatividade no VAB da agropecuária estadual. Resultado que indica que essas microrregióes possuem potencial para ampliarem a demanda por crédito rural afim de dinamizar ainda mais a agropecuária.

A partir disso, pode-se sugestionar que a distribuição do crédito rural não acompanhou proporcionalmente a participação relativa no valor adicionado da agropecuária entre as microrregióes. Todavia, embora a agricultura esteja presente em todas as regióes, identificam-se algumas concentrações regionais, as quais são determinadas pela participação das principais atividades no valor adicionado bruto da agricultura, como também ocorre em função das diferentes atividades econômicas desenvolvidas localmente. 
Ainda, os resultados demonstram que, na média, o estado teve uma participação maior no volume de crédito do que no valor adicionado da agropecuária nacional. Durante todo o período analisado, o IRCR do Rio Grande do Sul foi superior à unidade, tendo maior valor de 1,86, em 2005 e, desde então, o índice apresentou importante oscilação associado a uma tendência de queda, atingindo, em 2015, último ano da análise, o menor valor, de 1,22. Isto evidencia que, apesar de o Rio Grande do Sul configurar-se entre os estados com maior participação no crédito rural e também ser um dos primeiros colocados no ranking de participação no valor adicionado bruto da agropecuária do país, a distribuição heterogênea de crédito rural entre as regiões, em alguma medida, está limitando o potencial de crescimento da atividade agropecuária.

Esta situação aponta a necessidade contínua de acompanhamento das políticas públicas nacionais e locais para que alcancem seus objetivos de fomentar a produtividade da comercialização, bem como a redução de custos, além de desenvolver estratégias para a agregação de valor à produção sejam alcançados. Também serve à formulação de novas políticas de créditos ligadas à tecnologia, à inovação e à gestão de propriedades rurais. Depreende-se também que, além da necessidade de uma maior desconcentração de recursos do crédito rural, são necessárias alteraçôes nas condicionalidades na concessão desses recursos para que não haja incentivo à inadimplência e para que a concessão de crédito não fomente o aumento do desmatamento.

Embora os resultados tenham possibilitado a obtenção de informações relevantes, algumas limitações devem consideradas, caso da utilização dos valores totais do crédito rural sem desagregá-los por finalidades de uso ou por categorias. Assim, sugere-se, em estudos futuros, analisar de forma mais ampla as finalidades de crédito rural: comercialização, custeio, investimento e agroindústria ou a distribuiçãao espacial do crédito rural por programas específicos. Também se sugere a aplicação de metodologias que permitem verificar se há algum efeito de transbordamento dos efeitos de distribuição de uma região a outra. 


\section{Referências}

ALMEIDA, P. N. A.; LIMA, R. A. S.; SANTOS, V. C.; ALMEIDA, A. F. C.; SHIROTA, R. Concentração do Crédito Rural no estado da Bahia no período de 1999 a 2003. In: Congresso da Sociedade Brasileira de Economia, Administração e Sociologia Rural, 46, 2008, Rio Branco. Anais. Rio Branco: SOBER, 2008, p. 1-14. Disponível em: $\langle$ https://core.ac.uk/reader/6525115〉. Acesso em: $\mathrm{O} 2$ out. 2019.

ASSUNÇÃO, J.; GANDOUR, C.; ROCHA, R. Crédito afeta desmatamento? Evidência de uma política de crédito rural na Amazônia. Núcleo de Avaliação de Políticas Climáticas, PUC-Rio, 2013.

\section{ATLAS SÓCIOECONÔMICO DO RIO} GRANDE DO SUL. Disponível em: https:// bit.ly/3hozr49. Acesso em 22 de novembro de 2019.

BACHA, C.J.C. Economia e política agrícola no Brasil. São Paulo: Atlas, 2004.

\section{BANCO CENTRAL DO BRASIL. Anuário}

Estatístico do Crédito Rural (2005 a 2012). 2019a. Disponível em: https://bit. ly/3gm3wzV. Acesso em: 10 set. 2019.

BANCO CENTRAL DO BRASIL. Matriz de dados do crédito rural (2013 a 2015). 2019b. Disponível em: https://bit.ly/2EdqrAC. Acesso em: 10 set. 2019.

BARROS, E. S.; XAVIER, L. F.; PESSOA, D. T.; SOBEL, T. F. Endividamento agrícola: quão comprometido são os produtores do Polo Petrolina-Juazeiro frente suas dívidas? Revista Economia Aplicada, v. 19, n. 1, p. 171200, 2015.

BELIK, W. O financiamento da agropecuária brasileira no período recente. Texto para Discussão. Brasília Rio de Janeiro: Ipea, n. 2028, p. 1-57, 2015. Disponível em: https://bit.ly/34qnNSx. Acesso em: 25 set. 2019.

CROCCO, M. A.; NOGUEIRA, M.; ANDRADE, C. M. C. de; DINIZ. G. F. C. O Estudo do gap regional de crédito e seus determinantes, sob uma ótica pós- keynesiana. Revista Economia, v. 12. n. 2, p. 281-307, 2011.

FAGUNDES, T. T.; VIANA, J. G. A. Evolução do Crédito Rural no Rio Grande do Sul: análise geral e setorial entre 2006 a 2016. Trabalho de Conclusão de Curso, UNIPAMPA, Santana do Livramento, 2017.

FEE - Fundação de Economia e Estatística Siegfried Emanuel Heuse. Indicadores. PIB Municipal - Série Histórica (2005 - 2015). 2019 Disponível em: https://bit. ly/3aQnoLM. Acesso em: 10 set. 2019.

FEIX, R. D.; LEUSIN JÚNIOR, S. Painel do agronegócio no Rio Grande do Sul - 2019. Porto Alegre: SEPLAG, DEPARTAMENTO DE ECONOMIA E ESTATÍSTICA, 2019. Disponível em: https://bit.ly/3lkLA4p. Acesso em: 01 out. 2019.

GALEANO, E. A. V.; SILVA, A. E. S.; SOUZA, R. C. Índice regional de crédito rural nos municípios do Espírito Santo. Revista de Política Agrícola, v. 26, n. 4, p. 50-70, 2017. HOFFMANN, R.; KAGEYAMA, A.A. Crédito rural no Brasil: concentração regional e por cultura. Revista de Economia Rural, v. 25, n. 1, p. 31-50, 1987.

IBGE - Instituto Brasileiro de Geografia e Estatística. Divisão regional do Brasil. 2020. Disponível em: https://bit. ly/2EjPzWh. Acesso em: 16 abr. 2020.

JESUS, T. U. A.; CASTRO, E. R. Desigualdade na distribuição do Crédito Rural entre as regiões e municípios do estado de São Paulo. In: Encontro Nacional de Economia, 40., 2012, Porto de Galinhas. Anais. Porto de Galinhas: ANPEC, 2012. Disponível em: https://bit.ly/31olOMw. Acesso em: 28 set. 2019.

MAPA - Ministério da Agricultura Pecuária e Abastecimento. Política Agrícola. Informações Gerais sobre Crédito Rural. Brasília. 2019. Disponível em: https://bit. ly/32nL9We. Acesso em: 29 set. 2019. 
MATTEI, L. Evolução do crédito do Pronaf para as categorias de agricultores familiares A e A/C entre 2000 a 2010. Revista Econômica do Nordeste, v. 45, n. 3 p. 58-69, 2014.

MELO, L. B.; RESENDE FILHO, M. A. Determinantes do risco de crédito rural no Brasil: uma crítica às renegociações da dívida rural. Revista Brasileira de Economia, v. 71, n. 1, p. 67-91, 2017.

\section{MINISTÉRIO DA ECONOMIA. Política} Agrícola e Meio Ambiente. Crédito Rural. Brasília. 2018. Disponível em: https://bit. ly/3lldUUc. Acesso em: 15 de set. 2019.

MORAES, J. L. A.; MEDEIROS, A. M.; MATTE JR, A. A. Resultados do uso do crédito rural (PRONAF) pelos agricultores familiares de Santo Antônio da Patrulha RS. Estudos do CEPE, n. 47, p. 64-80, 2018. Disponivel em: https://bit.ly/2QpKON7. Acesso em: 15 de set. 2019.

OLIVEIRA, G. C.; WOLF P.J. W. A Dinâmica do mercado de crédito no Brasil no período recente. Texto para Discussão. Brasília - Rio de Janeiro: Ipea, n. 2243, p. 1-132, 2016. Disponível em: https://bit.ly/2QgqRII. Acesso em: 25 set. 2019.

OLIVEIRA, S. V.; OLIVEIRA, L. B.; PAULI, R. I. P. Disponibilidade e acesso ao crédito rural: a percepção dos produtores rurais do município de São Pedro das Missões (RS). Revista Sinergia, v. 22, n. 1, p. 51-63, 2018.
TATSCH, A. L. O processo de aprendizagem em Arranjos Produtos Locais: o caso do arranjo de máquinas e implementos agrícolas no Rio Grande do Sul. 2006. Tese (Doutorado em Economia) - Instituto de Economia, UFRJ, Rio de Janeiro.

SCHNEIDER, S.; WAQUIL, P.D.; KUHN, D.D.; MIGUEL, L de A. Microcrédito e capacidade de pagamento dos agricultores familiares: a experiência do Programa RSRural no Rio Grande do Sul. Revista Ensaios (FEE), v. 26, n. 2, p. 789-828, 2005.

SOBARRZO, O. A rede urbana da mesorregião noroeste do Rio Grande do Sul: o papel das cidades nos circuitos da agricultura modernizada. Revista GeoUECPrograma de Pós-graduação em Geografia da UECE Fortaleza/CE, v. 4, n. 7, p. 36-63, jul/dez. 2015.

SOUZA, P. M., NEY, M. G. e PONCIANO, N. J. Evolução da distribuição dos financiamentos do PRONAF entre as Unidades da Federação, no período de 1999 a 2009. Revista Brasileira de Economia, v. 65, n. 3, p. 303-313, 2011.

SOUZA, C. C. M.; SANTOS, M. A. S.; REBELLO, F. K. Espacialização e Concentração das aplicações de crédito rural no Brasil entre 2007 e 2017. Revista Agrarian Academy, Centro Científico Conhecer, v.5, n.10, p. 86, 2018.

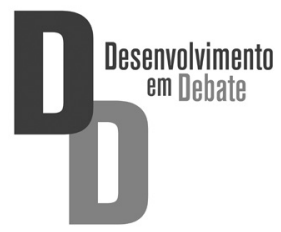

